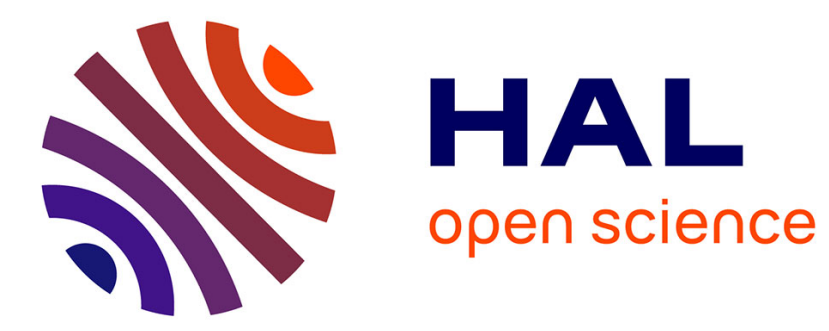

\title{
New contact material for reduction of arc duration for dc application
}

\author{
L. Doublet, N. Ben Jemaa, S. Rivoirard, C. Bourda, Erwann Carvou, D. \\ Sallais, D. Givord, P. Ramoni
}

\section{- To cite this version:}

L. Doublet, N. Ben Jemaa, S. Rivoirard, C. Bourda, Erwann Carvou, et al.. New contact material for reduction of arc duration for dc application. European Physical Journal: Applied Physics, 2010, 50 (1), pp.12901. 10.1051/epjap/2010018 . hal-00581867

\section{HAL Id: hal-00581867 https://hal.science/hal-00581867}

Submitted on 1 Apr 2011

HAL is a multi-disciplinary open access archive for the deposit and dissemination of scientific research documents, whether they are published or not. The documents may come from teaching and research institutions in France or abroad, or from public or private research centers.
L'archive ouverte pluridisciplinaire HAL, est destinée au dépôt et à la diffusion de documents scientifiques de niveau recherche, publiés ou non, émanant des établissements d'enseignement et de recherche français ou étrangers, des laboratoires publics ou privés. 


\title{
New Contact Material for Reduction of Arc Duration for DC Application
}

\author{
L. Doublet ${ }^{1, \text { a }}$, N. Ben Jemaa ${ }^{2}$, S. Rivoirard ${ }^{3}$, C. Bourda ${ }^{1}$, E. Carvou ${ }^{2}$, D. Sallais ${ }^{2}$, D. Givord ${ }^{4}$, P. Ramoni ${ }^{5}$ \\ ${ }^{1}$ Metalor Technologies (France) SAS, Electrotechnics Division, BP 29, 28190 Courville-sur-Eure, France \\ ${ }^{2}$ University of Rennes 1, IPR , 35042 Rennes, France \\ ${ }^{3}$ CRETA, CNRS, 25 avenue des Martyrs, 38042 Grenoble, France \\ ${ }^{4}$ Institut Néel/CNRS-UJF, 25 avenue des Martyrs, 38042 Grenoble, France \\ ${ }^{5}$ Metalor Technologies SA, Technology Products Department, 2009 Neuchâtel, Switzerland
}

\begin{abstract}
The phenomenon of arcing is the major cause of electrical contact degradation in electrical switches. Degradation involves contact erosion and/or welding. The use of special contact material and that of specific material processing may permit contact erosion to be reduced, in particular by shortening the arc duration. A short review of these approaches is presented in the first part of this paper. In the second part, the development of a new self-blowing contact material is described. This material has been tested under DC voltages from $14 \mathrm{~V}$ to $42 \mathrm{~V}$. A reduction of the arc duration by a factor of 4 approximately was obtained as was a concomitant reduction of the extinction gap to less than $2 \mathrm{~mm}$. This material will contribute to achieving better reliability in high current-high voltages breaking devices, and will aid in their miniaturization, e.g. in relays.
\end{abstract}

\section{Introduction}

The technical and economic reasons to increase the power levels of electrical circuits have been discussed in numerous papers. The associated voltage and/or current increase supported by the circuit results, in turn, in an increase in the arc duration, and subsequent extinction gap, during the breaking operation. Breaking devices have been developed having original designs or conception, which permit reduction in the arc duration, with consequent reduction in its deteriorating effect. In this paper, we show that it may also be possible to introduce an innovative material which generates an intrinsic magnetic field in the extinction gap, thus promoting self-blowing of the arc and a consequent reduction in its duration. After a brief review of what is an arc and well-known solutions (mechanical, electronic, material, ...) to reduce it, we present a self blowing material as a possible answer.

\subsection{Why break higher electrical power levels with usual break devices?}

The manufacturers of breaking devices ( $\mathrm{CB}$, relays, etc...) have cost reduction policies and try to reduce the range or size of their apparatus. One consequence is that each device must have a wide breaking capacity. Therefore, it is subjected to longer electrical arcing, which are more damageable for contacts materials. Moreover, these devices are submitted to increasingly severe constraints, such as reduced sizes and weight, in order to limit fuel consumption in automotive or aeronautic applications. The automotive sector also seeks to raise the voltage of the circuit on board to increase the capacity of electrical power and to supply a growing number of electrical devices. All these changes submit breaking devices, and especially the electrical contacts materials, to more severe electrical conditions.

\subsection{What are the consequences of an increase in current and / or voltage on breaking devices}

When the current is switched off by a breaking device, it generates an electrical arc which is broadly neutral plasma consisting of ionized species coming from the contacts material and from the surrounding environment (atmosphere, plastic parts...). It is a dynamic and unstable phenomenon. The main characteristics of this arc (duration and gap extinction, arc voltage and arc current) depend on the parameters of the electrical circuit, the parameters of the opening system (speed, design) and the nature of the elements close to the arc plasma which are able to come into the plasma and modify its composition (contact material, nitrogen or oxygen from atmosphere or materials from the case).

Figure 1 shows the arc duration curves for silver contacts versus wide current range $(0.1$ to $130 \mathrm{~A})$ at 14 , 42, 112 and 360VDC in resistive load. These results were obtained with the experimental electrical testing

\footnotetext{
${ }^{a}$ Laurent.doublet@metalor.com
} 
device described in previous papers [4] and briefly reminded \$2.1.2. Each curve has two parts: a first segment obeys to a power law with a high slope $\mathrm{I}^{4}$ and is followed by a flatten section. Let us consider the curve for $42 \mathrm{VDC}$. Up to $2 \mathrm{~ms}$, the arc duration versus current characterizes an arc in metallic phase (regime 1 or anodic arc) whereas at longer time it characterizes an arc in gaseous phase (regime 2 or cathodic arc) [5,6]. These effects were extensively discussed in previous publications. It is interesting to note that except at $14 \mathrm{VDC}$, the slopes of the first regime are parallel the ones to the others. It can be concluded that the same phenomena determine the arc behaviour in the whole voltage range from $42 \mathrm{VDC}$ to $360 \mathrm{VDC}$.

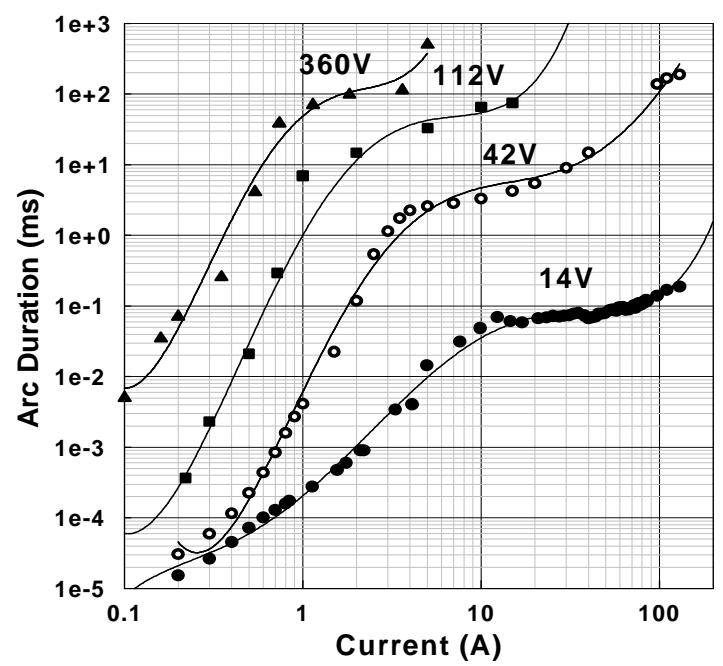

Fig. 1: Arc duration versus current in a range from 0.1 to up to $100 \mathrm{~A}$ at four circuit voltage $(14,42,112$ and 360VDC)

These results show that the arc durations can reach important values needing a wider extinction. If the contact gap, imposed by the design of the device, is smaller than the natural extinction gap of the arc, it may stagnate almost indefinitely until the contact materials totally melt. That can lead to the destruction of the device and cause fires for its direct environment. Beside this, when the natural extinction gap of the arc increases (because the arc is getting longer), the phenomena of transfer between contacts pass through the above mentioned anodic and cathodic regimes and thus, material loss is becoming increasingly large [7-11].

Due to these various reasons, if the next generations of breaking devices have to withstand harsher electrical arcs, they should be equipped with arc reducing (or suppression) systems.

\subsection{What are the most common arc suppression systems?}

By modifying certain parameters of the breaking device, it would be possible to control the arc duration and gap extinction. The electrical parameters of the circuit being imposed we can only act on the physicochemical parameters of the breaking device. The following (but non-exhaustive) list enumerates such actions and their principles that help to minimize the consequences of arcing.

\subsubsection{Atmosphere}

The atmosphere of the breaking can be ambient air, vacuum or under a protective gas, such as SF6. Alternatively, the contacts environment may be filled with oil. In the earlier moments of the arc, the plasma consists of species that come from the ionization of the contact material. The pressure of the plasma is tremendous (several tens of bars). As the contacts separate, the pressure decreases and the gas from the atmosphere enters into the plasma and becomes ionized. This supplementary source of electrons maintains the electrical conductivity of the plasma and slows down the decrease of the current. Depending on the nature of the atmosphere, its components are more or less ionizable: specific atmospheres other than ambient air are sometimes used because they promote the extinction of the arc by providing a lack of electrons (ex: SF6). Under vacuum, the contact material only feeds the plasma. Therefore, its intensity decreases as the two contacts are moving away. In this case, the gap extinction and arc duration are reduced.

\subsubsection{Kinematics}

It is well admitted that for a resistive AC or DC circuit, increasing the speed of contacts separation (e.g. for certain appliances, by changing the stiffness of the springs), reduces the arc duration and associated damages as well. Various physico-chemical processes compete during the opening of the contacts. Some of them act in favor of the stabilization of the current in the plasma and other work against this state of equilibrium. Beyond these phenomenon, opening the contacts contribute to the decrease of the current by increasing the plasma volume. The faster the separation, the stronger the current decrease. However, care should be taken in inductive load where the time constant of the inductance plays an opposite role and may increase arc duration at high speed $[4,12]$

\subsubsection{Horn arc contacts or sacrificial contacts}

These techniques reduce erosion on the main contacts. They limit their degradation and ensure good conduction (at the closed state) by limiting their temperature rise. Arc duration is not reduced but arc is deported in areas designed to withstand it.

\subsubsection{Arc chamber}

As it is the case in the circuit breaker, the developing arc moves to an arc chamber consisting of splitting plates where it is divided into multiple serial arcs. This promotes the arc voltage to increase and leads to rapid extinction.

\subsubsection{Double break}

In the design of the breaking devices, it is not uncommon to connect two pairs of contacts in series that will open simultaneously and will form two electric arcs. The energy of a single arc is almost divided by two and 
the damages are significantly reduced on the electrical contacts.

\subsubsection{Electronics systems}

It is possible to implement electronic systems, which detect arc ignition and provoke earlier arc extinction in the breaking devices. Some solid or electromechanical relays have been suggested in the literature [13].

All these specific features introduced in the design of devices involve the addition of arc suppression systems and/or a sealed box to contain atmospheres. They have a significant impact in terms of cost, size and weight.

\subsubsection{Material}

The choice of specific contact materials is complementary to the development of arc suppression systems. The influence of the contact material, though limited, reduces the extinction gap or the arc erosion regarding to the circuit parameters (AC/DC, voltage or current level), also the application of the circuit (protection or control). Because the influence of contact material occurs at the beginning of the arc, it is easy to compare different materials according to electrical circuit conditions.

In figure 2, six materials were tested on the laboratory bench described in paragraph 3.1.2. The experimental conditions were the following: 42VDC, $20 \mathrm{~cm} / \mathrm{s}$, and resistive load. For our comparison, $10 \%$ weight $\mathrm{MeO}$ were added to silver. We see that $\mathrm{AgSnO}_{2}$ has yielded the longest arcs, with a strong shift from 25A, while the $\mathrm{AgZrO}_{2}$ arc durations are lower. Besides $\mathrm{AgSnO}_{2}$, other materials in this current range, such as $\mathrm{AgNi}$ and $\mathrm{AgZnO}$, show a linear increase of the arc duration versus current. The additions of $\mathrm{Gd}_{2} \mathrm{O}_{3}$ and $\mathrm{ZrO}_{2}$ are good alternatives to the today widely used $\mathrm{AgSnO}_{2}$ [14].

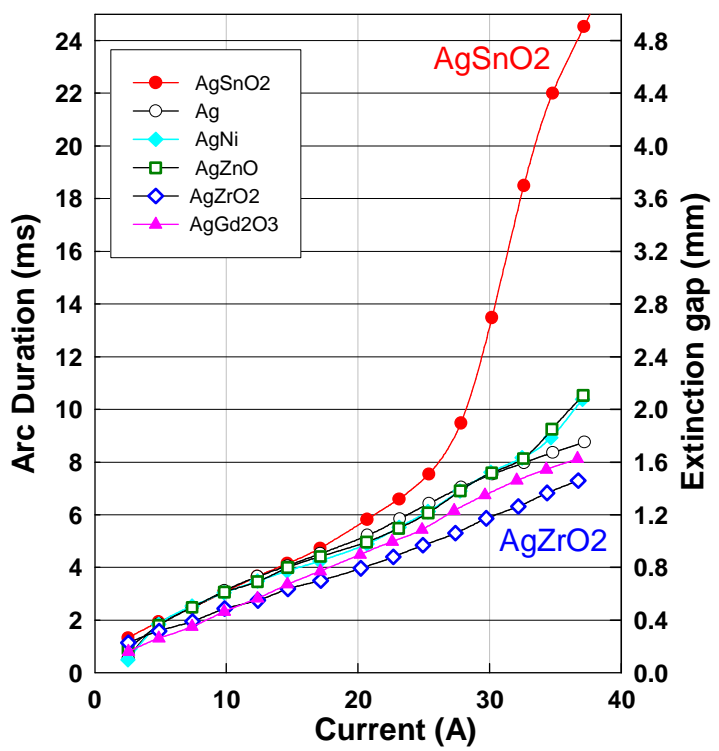

Fig. 2: 42VDC resistive, $\mathrm{t}=\mathrm{f}(\mathrm{I}), \mathrm{Ag}, \mathrm{AgNi}, \mathrm{AgSnO} 2, \mathrm{AgZnO}$, $\mathrm{AgGd} 2 \mathrm{O} 3, \mathrm{AgZrO} 2$

\subsubsection{Magnetic Blowing}

On some breaking devices, which should switch strong currents, magnetic blowing systems may be used. Most often, it is realized by introducing a serial coil on the circuit (close to the area of arc). Current flow in the coil produces a magnetic field oriented perpendicular to it and ensures arc evacuation from the contact area by producing a force orthogonal to both other directions, according to Lorentz law. Such magnetic blowing systems have been developed both for DC and AC applications depending on the targeted breaking capacity.

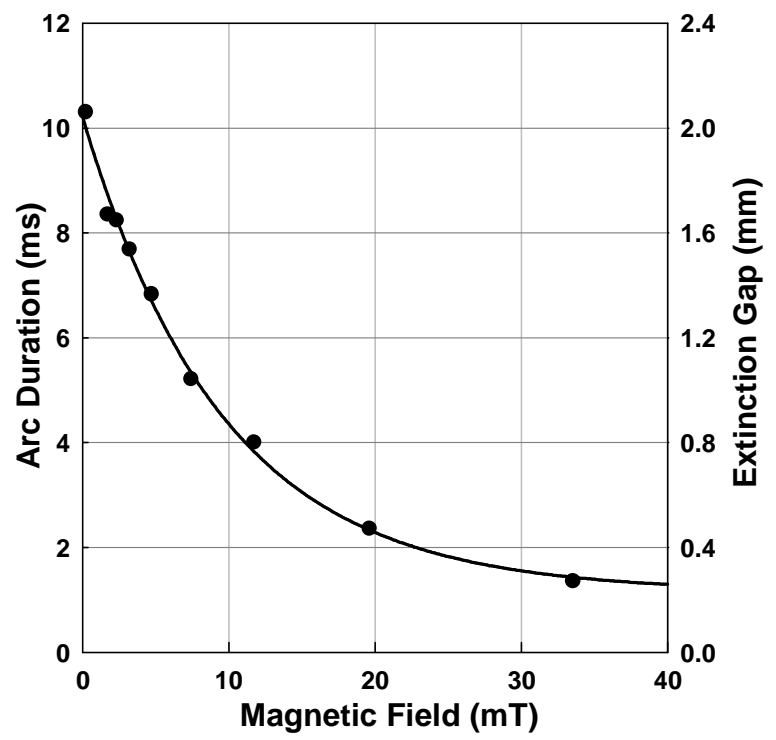

Fig. 3: Arc duration and extinction gap versus external magnetic filed for $\mathrm{Ag}$ at $42 \mathrm{VDC}, 37.5 \mathrm{~A}$ at $20 \mathrm{~cm} / \mathrm{s}$

Figure 3 shows the variation of the arc duration and extinction gap versus a uniform external magnetic field perpendicular to the current flow. These results were obtained on the electrical test device described in paragraph 3.1 .2 , on silver contacts at $20 \mathrm{~cm} / \mathrm{s}$ under 37.5A. Two magnets produced the magnetic field and it varied by changing the gap between the two magnets. Its value was measured using a Hall probe (sensitivity around $+/-0,2 \mathrm{mT}$ ) positioned in the magnet gap. In a second step, the Hall-effect probe was replaced by electrical contacts to obtain the data shown in fig. 3 .

Figure 3 shows that the arc duration at $0 \mathrm{mT}$ is in agreement with data in fig 2 . The arc duration decreases drastically as the magnetic field is increased. At $10 \mathrm{mT}$ it is already reduced by a factor of more than 2 . At longer time, it tends towards a limit value of about $1 \mathrm{~ms}$.

\section{Self-blowing material}

The purpose of this part is to present the study on the characteristics of a break arc, exploiting the selfblowing properties of a magnetic phase, introduced into the contact material. This new material permits higher breaking capacity to be reached than traditional materials without any change in the device design. 


\subsection{Equipment and procedure}

\subsubsection{Contact Material preparation and magnetic characterization}

Cylindrical samples with a diameter of $5 \mathrm{~mm}$ and a height of $5 \mathrm{~mm}$ were prepared by conventional powder metallurgy by mixing silver powder with magnetic material (for confidentiality reasons, we will not indicate here the physico-chemical the properties of the material used: nature, shape and mass content).

The samples were magnetized at room temperature in a super-conducting magnet with a maximum applied field of $\mu_{0} H=7 \mathrm{~T}$ (Oxford Company). The filed was applied along in the direction perpendicular to the cylinder axis. Figure 4 shows the characteristic hysteresis cycle of the phase magnetic used in our electric contact material.

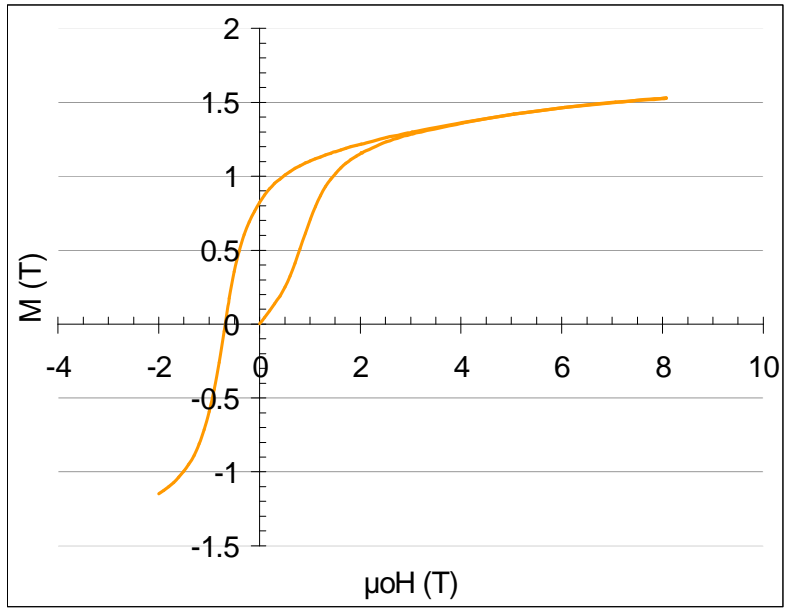

Fig. $4: \mathrm{M}=\mathrm{f}(\mu \mathrm{OH})$ for magnetic phase in electrical contact material

After magnetization, the surface induction of each sample, $B s$ was measured with a Hall probe (Lakeshore Company) placed at $1 \mathrm{~mm}$ above the surface sample. The samples were magnetized at three different levels corresponding to surface inductions of 30,55 and 100 $\mathrm{mT}$ respectively, as determined by the Hall probe. The samples were called AgMM1, AgMM2 and AgMM3, respectively.

\subsubsection{Electrical characterization by break arc duration}

The PALMS Laboratory of Rennes is equipped with a fully automated device (fig. 5), adapted to perform contact breaking under 14 VDC up to 360 VDC. This device has been described in details in previous papers [4,5]. In this paper, most experiments were performed under $42 \mathrm{VDC}$ and with a resistive load, at opening speed of $20 \mathrm{~cm} / \mathrm{s}$, i.e. under conditions similar to those of automotive relays. Voltage, current, loads and opening speed were controlled, and a digital oscilloscope stored voltage and current characteristics of the arc during the break. The arc parameters, namely arc energy, arc duration and extinction gap were thus deduced.

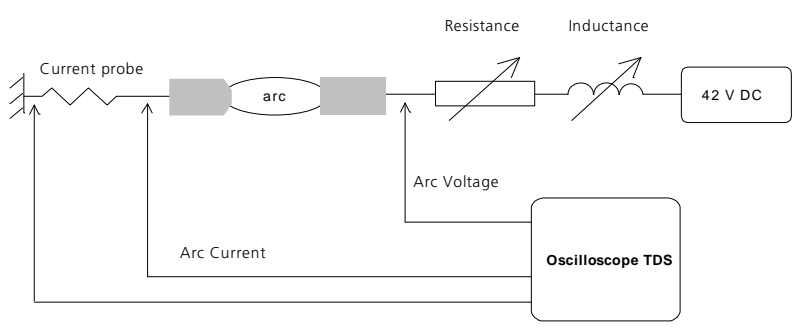

Fig. 5: Electrical test apparatus for break arc

For all the experiments, the magnetic material AgMM was placed at the cathode and pure silver at the anode: figure 6 shows the position of the cathode and the anode in the electrical tests. The respective directions of the current, I, the magnetic induction of the sample, B, and the resulting Lorentz force, $\mathrm{F}$ are indicated in the fig.6.

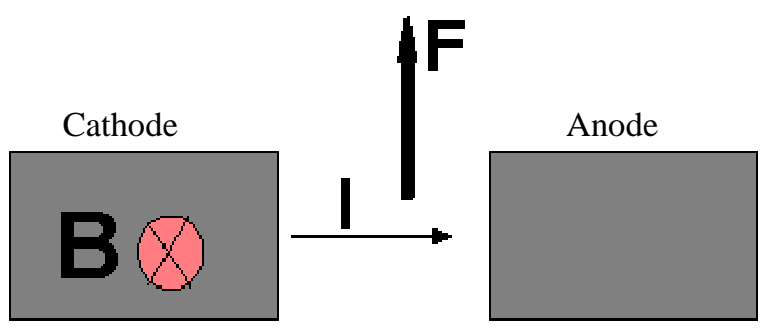

Fig. 6: Sample geometry used during the electrical tests

\subsection{Results and discussion}

Figure 7 shows the evolution of arc voltage versus time under 37,5A, 42VDC and a resistive load for the following contacts materials: $\mathrm{AgSnO}_{2}$, pure $\mathrm{Ag}$ and AgMM3. The arc voltage increases slowly with time for AgSnO2 and a little faster for silver. The total arc duration are $24 \mathrm{~ms}$ and $8 \mathrm{~ms}$ respectively. By contrast, with AgMM the arc duration is reduced down to $3 \mathrm{~ms}$ only. The reduction with respect to the case of silver contact illustrate the blowing effect of the magnetic field.

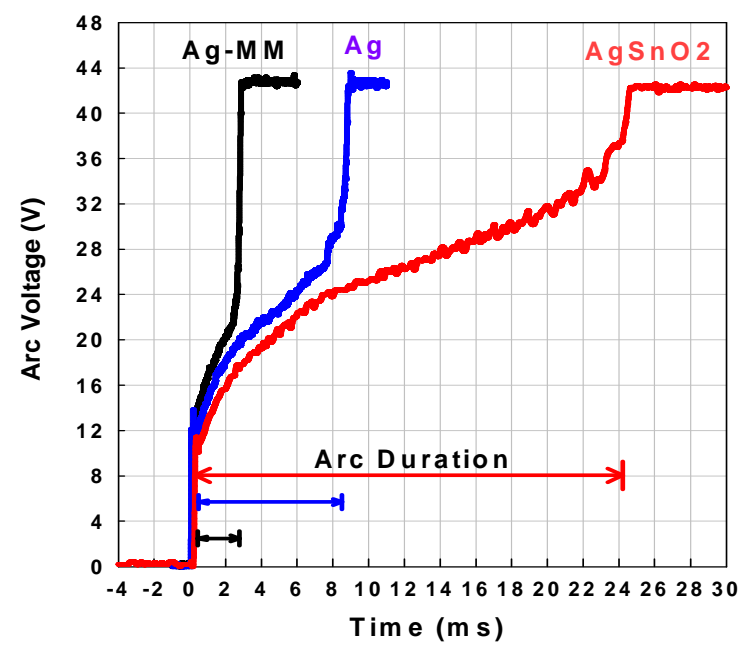

Fig. 7: Arc voltage versus time for $\mathrm{AgSnO} 2, \mathrm{Ag}$ and $\mathrm{AgMM} 3$ at 42VDC, 37.5A resistive 
Figure 8 shows the evolution of the extinction gap, as a function of the current, for pure silver contacts on the one hand and silver magnetic contacts on the other hand. The three magnetic materials differ only by the magnetic field they produce. The stronger the magnetic field, the lower the arc duration. Optimum properties are obtained with the arc length of AgMM3 which is the contact producing the highest magnetic field. Under $37,5 \mathrm{~A}$, the arc duration is reduced down to $2,4 \mathrm{~ms}$, $72,5 \%$ less than with pure silver. For AgMM1, which produces the weakest magnetic field, the blowing effect starts around 10A only. In the case of AgMM2 and AgMM3, the blowing effect begins earlier. The reason is that for higher magnetic field, the curved radius of the trajectory of an electron is smaller.

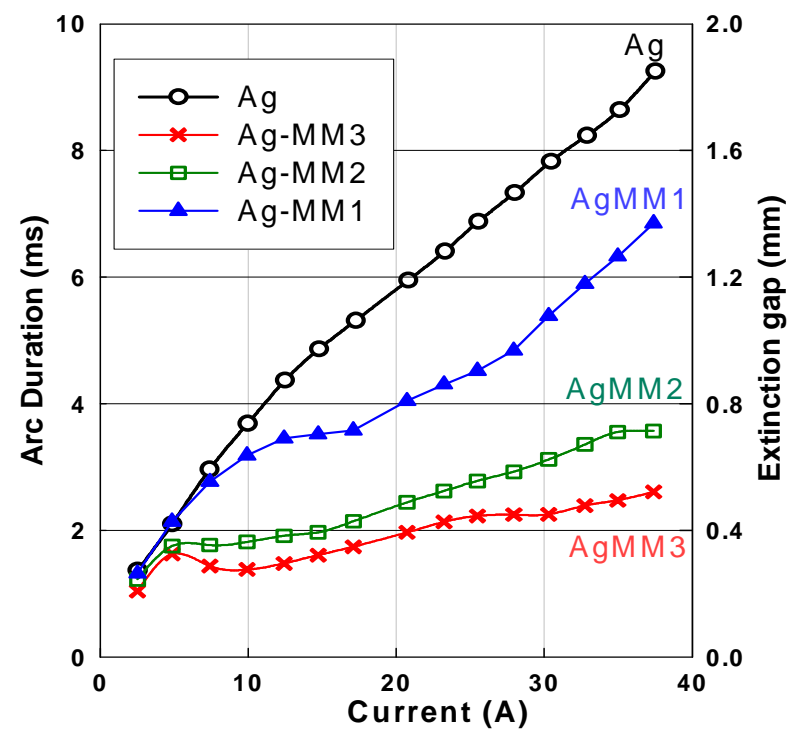

Fig. 8: Arc duration versus Current for Ag, AgMM1, AgM2 and $\mathrm{AgMM} 3$ at $20 \mathrm{~cm} / \mathrm{s} 42 \mathrm{VDC}$ resistive

Figure 9 shows the evolution of the arc duration as a function of the magnetic field. The value at $0 \mathrm{mT}$ does correspond to the arc duration for pure silver.

Qualitatively, the curve is similar to the one shown on fig 3. The magnetic field scales do not correspond one to the other. This is simply due to the fact that the field measured on the contact surface with the Hall probe (fig 9) is not the field measured in the gap (fig. 3).

It remains that with AgMM3 a spectacular reduction in the arc duration is obtained at 2,4 $\mathrm{ms}$ which corresponds to $\sim 480 \mu \mathrm{m}$ of extinction gap $(\mathrm{v}=20 \mathrm{~cm} / \mathrm{s})$.

All together, the use of magnetic contact permits arc blowing through the Lorenz force, as it is the case in the classical systems using permanent magnets or coils.

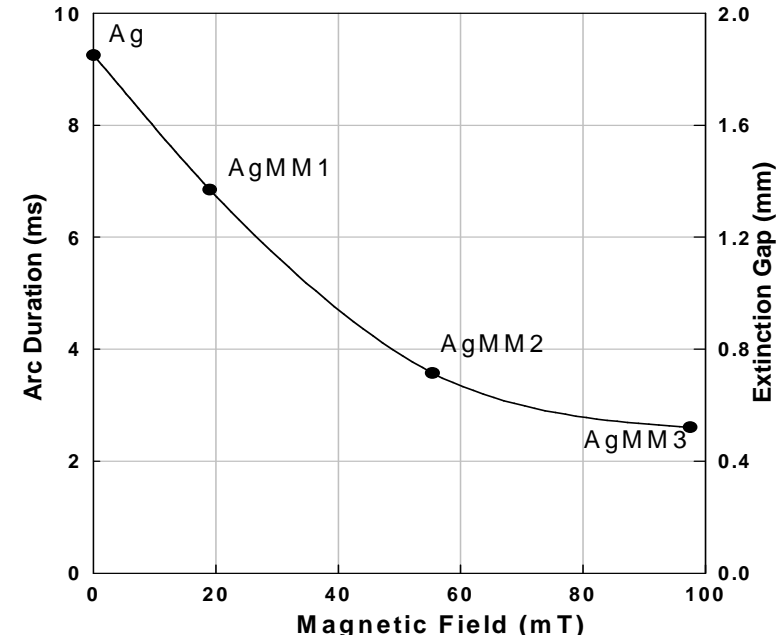

Fig. 9: Arc duration versus Magnetic field for Ag, AgMM1, AgMM2 and AgMM3 at $20 \mathrm{~cm} / \mathrm{s} 42 \mathrm{VDC}, 37.5 \mathrm{~A}$ at $20 \mathrm{~cm} / \mathrm{s}$

Figure 10, shows arc durations versus number of operations at 42VDC \& $37.5 \mathrm{~A}$ for a resistive load. Results are compared for pure silver and the three types of magnetic contacts. In all cases, the average arc duration shows a slow decrease during the first thousand operations. Nevertheless, the efficiency of magnetic blowing was preserved up to final testing. This is very encouraging despite the fact that the maximum 6000 operations considered here is much less than the millions of operations, which a relay must usually undergo. It is also noticeable that the dispersion in arc duration is larger for pure silver than for all magnetic contact material including AgMM1, which produces the weakest magnetic field.

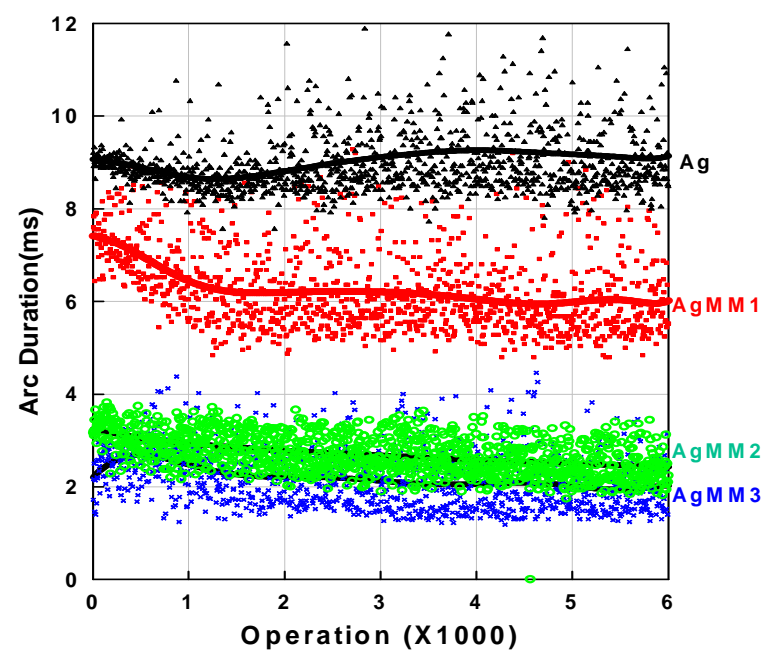

Fig. 10: Arc duration versus number of break operations for $\mathrm{Ag}$, AgMM1, AgMM2 and AgMM3 at 20cm/s 42VDC, 37.5A at 20cm/s 


\section{Conclusions and perspectives}

A new contact material has been developed which generates an intrinsic magnetic field in the extinction gap and leads to much faster current breaking. With fully magnetized materials (generating the largest magnetic field in our conditions), the average arc duration was reduced by a factor of 4 compared to that obtained with silver contacts. The reduction in the arc duration was already very significant with non fully-magnetized materials. The decrease in the extinction gap under field tends towards a non-zero limit value [extrapolated to around $200 \mu \mathrm{m}$ (and 1ms) from Fig. 3]. This implies that below a certain minimum distance the magnetic field blowing effect disappears (in our conditions). The dispersion in the blowing efficiency was characterized over at least 6000 operations, in the case of fullymagnetized materials. It is already planned to characterize further the material limits by increasing the severity of all electrical parameters during testing.

It is hoped, on the one hand, that the reduction in the extinction gap obtained with this new material will permit breaking device miniaturization. On the other hand, the reduction in the arc duration should lead to a strong reduction in contact erosion. Thus, an increase in the device lifetime and a reduction in the volume of contact material may be expected, leading to significant cost reduction.

Further studies have started, addressing the mechanism of arc breaking and the process of material erosion, as well as arc initial formation, contact heating and welding. The contact itself is being further optimized with respect to its shape and nature.

Finally, as the blowing efficiency is also dependent on the environment of the contact material, testing of this new material in real breaking devices is programmed.

Acknowledgments : We are grateful to Justine Bernard for the samples preparations as well as the "magnetic" measurements.

\section{References}

[1] E. Carvou, N. Ben Jemaa "Electrical arc study in the range of $14-112 \mathrm{vdc}$ for automotive power contacts" Proc. of the 23rd International Conference on Electrical Contacts; Sendai (Japan), pp 28-33, 2006.

[2] D. Sallais, N. Ben Jemaa, E. Carvou, "An arc study at high DC current in automotive applications", IEEE Transactions on Components and Packaging Technologies, Vol. 30, Num. 3, pp. 540-54,5 septembre 2007.

[3] N. Ben Jemaa, L. Doublet, T. Schoepf, F. Hauner, D. Jeannot, «Arc duration and contact erosion in automotive
42VDC network », Proc. 50 $0^{\text {th }}$ Int. Relay Conf., Newport Beach, pp. 51-57, April 2002.

[4] L. Doublet, N. Ben Jemaa, F. Hauner, D. Jeannot, "Electrical arc phenomena and its interaction on contact material at 42 volts dc for automotive applications", Proc. 50th IEEE Holm Conf. On EC, Seattle, pp.8-14, Sept. 2004.

[5] P.J. Boddy and T. Utsumi, "Fluctuation of Arc Potential Caused by Metal-vapor Diffusion Arcs in Air", J. Appl.Phys., Vol. 42, No 9, pp. 3369-3373 (1971).

[6] N. Ben Jemaa, J.L. Queffelec, D. Travers, "Some investigations on slow and fast arc voltage fluctuations for contact materials proceeding in various gases and direct current", IEE Trans. on Comp., Hybrids, Manuf. Techn., vol.14, no.1, pp.113-117, March 1991.

[7] N. Ben Jemaa, L. Morin, S. Benhenda, L Nedelec, "Anodic to cathodic arc transistion according to break arc lengthening", IEEE Trans. Comp. Pack. Man. Tech., Part A, Vol. 21, \#4, pp. 599-602, decembre 1998.

[8] L. Doublet, N. Ben Jemaa, B. Mitchell, D. Jeannot, "Erosion and material transfert under 42VDC", Proc. 21, ICEC Zurich (Switzerland), pp/ 62-68, 2002.

[9] V. Behrens, T. Honig, A. Kraus, O. Lutz, "Switching behavior of silver based contact material in 42VDC applications", Proc. 21, ICEC Zurich (Switzerland), pp/ 69-74, 2002.

[10] J. Swingler, J. McBride, "The net zero mass loss on opening switching contact with AC Loading", IEEE Trans. Comp. and Pack. Tech., Part A, Vol. 22, pp. 27-37, march 1999.

[11] Z. Chen, K. Sawa, "Effect of arc behavior on material transfert : review", Proc. 42th Conf. on Electrical Contact, pp. 238-251, Chicago, September 1996.

[12] D. Sallais, N. Ben Jemaa, E. Carvou, "Minimization of arc extinction gap in the opening speed range $1 \mathrm{~cm} / \mathrm{s}-1 \mathrm{~m} / \mathrm{s}$ ", Proc. 53rd IEEE Holm Conference on Electrical Contacts, Pittsburgh, pp. 239-243, Sept. 2007.

[13] T. J. Schoepf, M. Naidu, S. Gopalakrishnan, "Mitigation and analysis of arc faults in automotive DC netwoks", IEEE Trans. on Components and Packaging Technologies, Vol. 28, pp. 319-326, 2005

[14] D. Sallais, N. Ben Jemaa, A. Perrin, T. Heraud, D. Jeannot, C. Bourda, "New silver-oxide composites to reduce break arc duration and its subsequent damages", Proc. of the 23rd International Conference on Electrical Contacts; Sendai (Japan), pp 178-283, juin 2006. 